\title{
Interlayer-free Silica-carbon Template Membranes from Pectin and P123 for Water Desalination
}

\author{
Isna Syauqiyah ${ }^{1}$, Muthia Elma ${ }^{1, *}$, Meilana D. Putra ${ }^{1}$, Aulia Rahma $^{2}$, Amalia E. Pratiwi ${ }^{2}$ \\ and Erdina L. A. Rampun ${ }^{2}$ \\ ${ }^{1}$ Chemical Engineering Department, Faculty of Engineering, Lambung Mangkurat University, 70714 \\ Banjarbaru, Indonesia \\ ${ }^{2}$ Chemical Engineering Magister Program, Faculty of Engineering, Lambung Mangkurat University, \\ 70714 Banjarbaru, Indonesia
}

\begin{abstract}
For the first time the interlayer-free silica-carbon templates membrane has been successfully fabricated employed pectin as carbon source. This membrane was compared to interlayer-free silica-P123 membrane that were fabricated via Rapid Thermal Processing (RTP). The aim of this work is to investigate the performance of interlayer-free silicapectin and silica-P123 membranes. Sol-gel process has been utilised to produce silica thin film using TEOS as precursor, EtOH, $\mathrm{HNO}_{3}$ and $\mathrm{NH}_{3}$ with two-step acid-based catalyst $\left(50{ }^{\circ} \mathrm{C}, 3\right.$ hours). Pectin and $\mathrm{P} 123$ were templated into silica sols. Subsequently, the alumina tubular support membranes were dip-coated into these sols and calcined at $400{ }^{\circ} \mathrm{C}$ (pectin) and $350{ }^{\circ} \mathrm{C}(\mathrm{P} 123)$, respectively with 4 layers each membrane. The interlayer-free silica-pectin shows excellent water flux $\left(5.73 \mathrm{~kg} \mathrm{~m}^{-2} \mathrm{~h}^{-1}\right)$ in comparison to interlayer-free silica-P123 (1.449 $\left.\mathrm{kg} \mathrm{m}^{-2} \mathrm{~h}^{-1}\right)$. Both silicapectin and silica-P123 membranes show very good salt rejection $(>99 \%)$. The performance of silica-pectin membrane is much better than silica-P123 membrane ( 4 times higher). It is influenced by the length of carbons chains where carbon chains of pectin is much lower than P123. Due to that, P123 connected to silica networks create dense film of membrane and reduce the membranes performance.
\end{abstract}

Keyword. Interlayer-free, silica-pectin, silica-P123, water desalination

\section{Introduction}

Water scarcity is the most crucial problem which facing a whole the world due to growth global population. Over the last decade, membrane desalination using pervaporation has been used to provide potable water. Pervaporation has offering several advantages such as high selectivity, low operation cost and can be operated at low pressure [1]. Silica is one of membrane type that most applied for pervaporation. However, the silica membranes have a limitation related to the low hydro-stability [2]. It is due to a high concentration of silanol

* Corresponding author: melma@ulm.ac.id 
group $(\mathrm{Si}-\mathrm{OH})$ was found in silica network [3]. Silanol is hydrophilic properties that react to the water molecules. It could bring the membrane pore collapse and will be affected to decrease of membrane performance [4]. Several studies have been developed to improve the performance of silica membranes such as hybrid organic-inorganic material [5], incorporation of metal oxide into silica network [6] and carbon template silica [7].

Previous work has showed the silica membranes hydro-stability was improved by embedded carbon from P123 materials into silica matrices. As a result, it shows excellent water flux $(8.5 \mathrm{~kg} \mathrm{~m}-2 \mathrm{~h}-1)$ and best salt rejection $>99.5 \%$ were higher compare to pure silica membranes [5]. Unfortunately, silica-P123 membrane has high production cost. In order to study carbon types material, a novel approach toward pectin could be an option as a carbon source instead synthetic material. Pectin is use as low cost natural carbon precursor and easy to obtain from fruit peels and industries waste [8]. Apple pomace have amount of pectin content $\sim 3.5-14.3 \mathrm{wt} \%$ [9] and also providing large active surface area [10].

Practically, membranes were coated on $\gamma-\mathrm{Al} 2 \mathrm{O} 3$ interlayer with medium pore size (approximately up to $0.05 \mu \mathrm{m}$ ) deposited onto substrate (up to $0.5 \mu \mathrm{m}$ ) via slow calcination rate called conventional thermal processing (CTP) [11]. However, it required more than one week of production time. In order to reduce cost and production time, Elma, Wang [5] have been developed membrane without any interlayer called interlayer-free membranes, the sols were simply dip-coated onto membrane substrates without employing interlayer. It is then directly calcined by using rapid thermal processing (RTP) which only spend less than 1 day of production time if compare to CTP method. Therefore, this work proposes a novel of interlayer free silica-pectin and silica-P123 membranes fabrication in order to reduce cost as well as to investigate the effect of pectin and P123 as carbon templates for water desalination. Hence, the aim of this study is to investigate the performance of interlayer-free silica-pectin and silica-P123 membranes

\section{Material and methods}

\subsection{Chemical and materials}

Silica sol were prepared by dual catalysed acid-base via sol gel method using tetraethyl orthosilicate (TEOS, $99.0 \%$, Sigma-Aldrich) as precursor of silica. Pectin from apple (Sigma Aldrich) as carbon templating agent. Ethanol (EtOH, 99\%) and aquadest as solvents, dilute nitric acid (0.0008 $\mathrm{M} \mathrm{HNO}_{3}$, Merck) and ammonia (0.0003 $\mathrm{M} \mathrm{NH}_{3}$, Merck) as acid and base catalysed and glycerol $85 \%$, Merck to dilute pectin, Triblock copolymer Pluronic ${ }^{\circledR} \mathrm{P} 123$. Also, $\mathrm{NaCl}$ solution of $3.5 \mathrm{wt} \%$ as feed that represented seawater and liquid nitrogen to condense water vapor to be liquid.

\subsection{Xerogels synthesis and characterisation}

Silica-pectin and silica-P123 sols were processed using two-step acid-base as catalysts via sol-gel method was adapted to our previous work of Elma, Wang [12] but in this procedure RTP method was used instead of CTP. Silica sol in this work was prepared by dropping wisely the TEOS into ethanol (EtOH, 99\%) and stirred for $5 \mathrm{~min}$ in cold condition $\left(0^{\circ} \mathrm{C}\right)$ and followed by adding drop wise $\mathrm{HNO} 3$ and refluxed for $1 \mathrm{~h}$ at $50{ }^{\circ} \mathrm{C}$. Diluted of $\mathrm{NH}_{3}$ was added into the solution and stirred for $2 \mathrm{~h}$ at the same condition and $\mathrm{pH} 6$ pure silica sol was obtained. 
For pectin prepared, first the pectin powder was diluted into glycerol at $40^{\circ} \mathrm{C}$ for 45 minutes. Finally, the mixed of pectin $(0.1 \mathrm{wt} \%)$ and glycerol was templated into pure silica sol which have been obtained previously. The same procedure also conducted for P123 sol but with added the triblock copolymer (35 wt $\%$ ) into pure silica sol. Sol was conducted with the final molar ratios is the TEOS:EtOH: $\mathrm{HNO}_{3}: \mathrm{H}_{2} \mathrm{O}: \mathrm{NH}_{3}: \mathrm{Y}$, where the final ratio calculated to be 1:38:0.0008:5:0.0003:Y and $\mathrm{Y}$ is ratio of pectin (0.000026) and $\mathrm{P} 123$ (0.00024).

Both silica-pectin and silica-P123 sols were dried in the oven for $24 \mathrm{~h}$ in a temperature controlled at $60{ }^{\circ} \mathrm{C}$. Then the dried gel of Si-pectin and Si-P123 (xerogels) were grounded into powder and calcined in air condition for $1 \mathrm{~h}$ at $400{ }^{\circ} \mathrm{C}$ and $350^{\circ} \mathrm{C}$, respectively. The vibrational bands and peak wavelengths of silanols, siloxanes and carbon were investigated by ATR-FTIR. This method was at the wavelength range between $400-4000 \mathrm{~cm}^{-1}$ to perform the FTIR spectra for 30 scans (ATR-FTIR type Bruker Alpha. Instrument type: alpha sample compartment RT-DLaTGS accessory: ATR platinum Diamond 1 Relf). The deconvolution peaks were measured by using the Fityk program with Gaussian peak fitting as the preferred curve.

\subsection{Membrane preparation}

Silica carbon template (Si-pectin and $\mathrm{Si}$-P123) sols were coated four times onto macroporous alumina substrates $\left(\alpha-\mathrm{Al}_{2} \mathrm{O}_{3}\right.$ tubular support (Ceramic Oxide Fabricators, Australia)) with average pore size is $100 \mathrm{~nm}$. After the deposition of each coating, the membrane layer was calcined via rapid thermal processing (RTP) techniques according to the [13-15] as can be seen in Fig. 1.

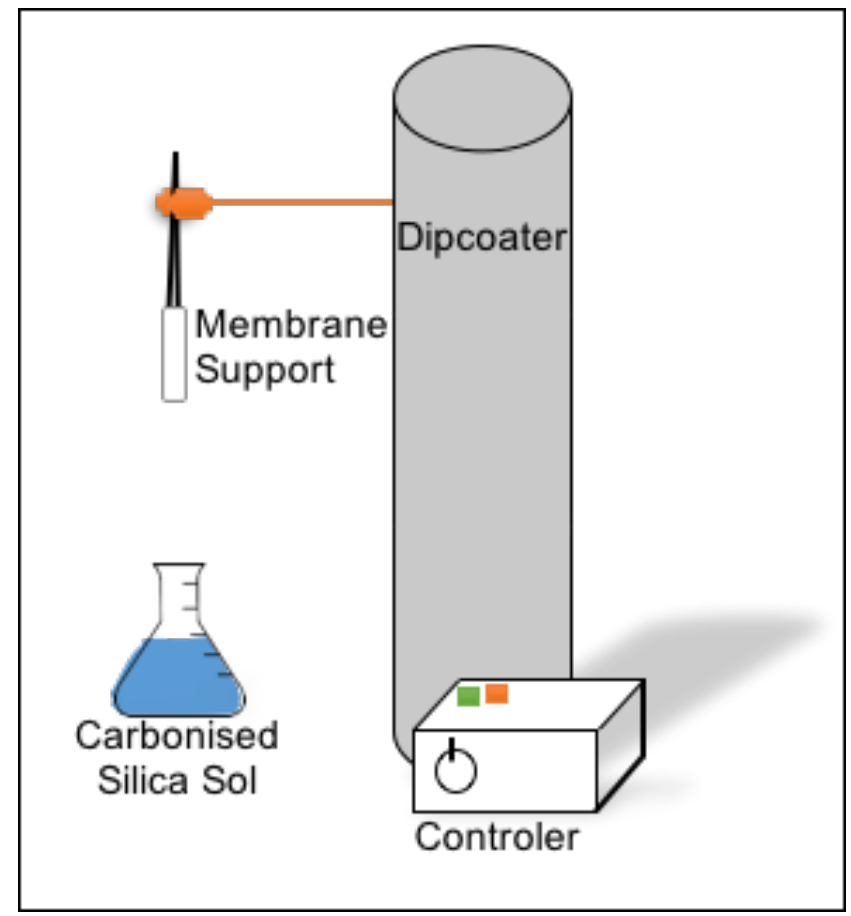

Fig. 1. Schematic of dip-coating process 
The membrane performance was measured by desalination application via pervaporation method using in seawater $(3.5 \% \mathrm{wt})$. The set-up of desalination via pervaporation mode were prepared as described in Fig. 2. Membrane was submerged into feed solution $\left(\mathrm{NaCl}, 3.5 \% \mathrm{wt}\right.$, Sigma-Aldrich) at room temperature $\left(25 \pm 2{ }^{\circ} \mathrm{C}\right)$. The calcined membrane was set up by dead end mode and connected to vacuum line with absolute pressure 1 bar. Stirrer was used for mixing homogeneously feed solution to avoid concentration polarisation. The water flux, $F\left(\mathrm{~kg} \mathrm{~m}^{-2} \mathrm{~h}^{-1}\right)$ can be obtained with measured the permeate and then can be calculated based on equation (1):

$$
F=\frac{m}{(A \Delta t)} \%
$$

Where $m$ is permeated mass $(\mathrm{kg})$ retained in the cold trap, A is surface-active area of membrane $\left(\mathrm{m}^{2}\right)$ and $\Delta \mathrm{t}$ is operation time (h). The salt rejection, $\mathrm{R}(\%)$, was determined based on equation (2):

$$
R=\frac{\left(C_{f}-C_{p}\right)}{C_{f}} \times 100 \%
$$

Where $C_{f}$ and $C_{p}$ are the feed and permeate concentrations were correlated to conductivities of the retentate and permeate solutions determined by a conductivity meter (OHAUS SF300C-G).

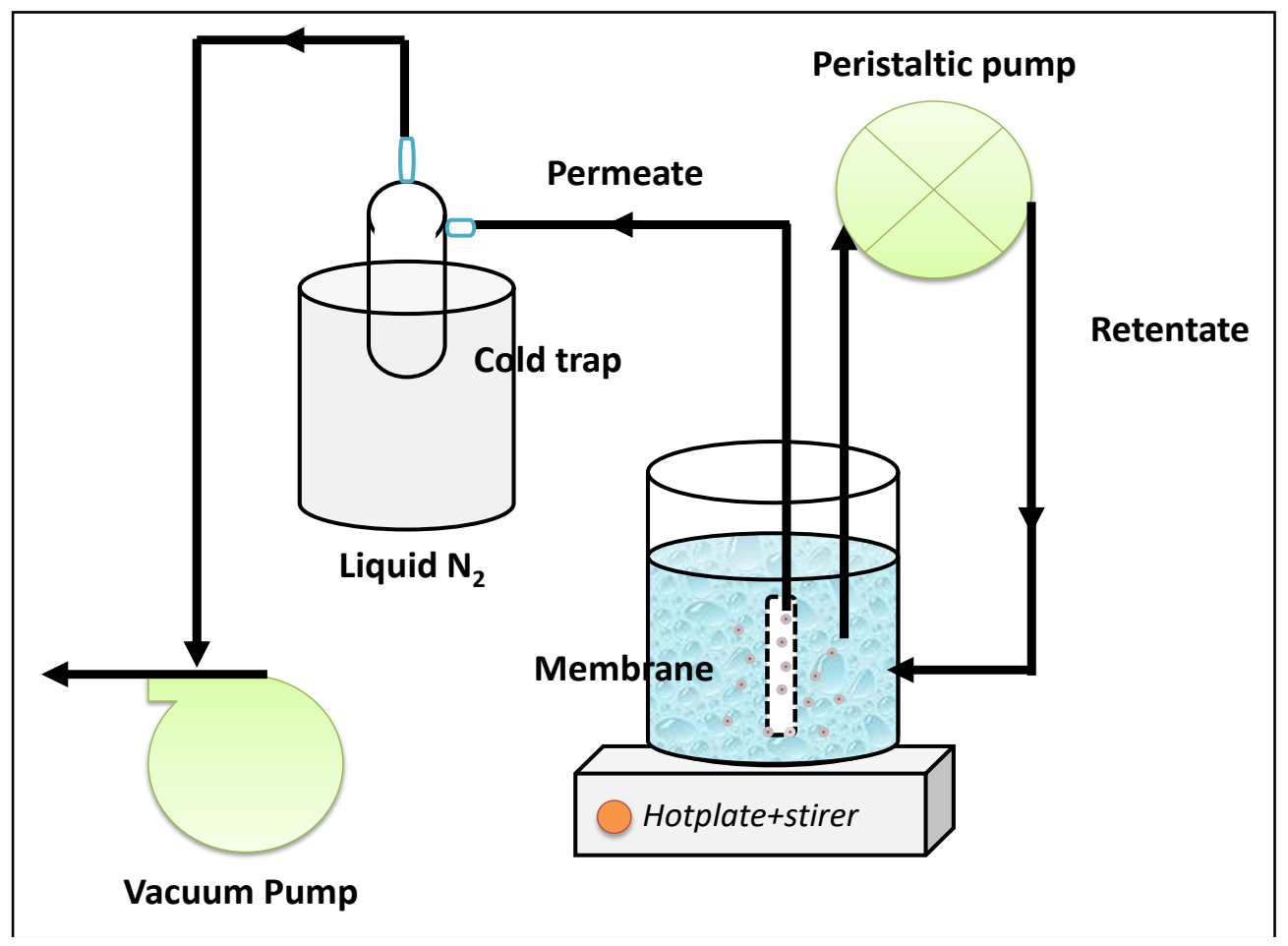

Fig. 2. Schematic of membrane pervaporation set-up for desalination 


\section{Results and discussion}

\subsection{Chemical and materials}

The evolution of chemical structure, particularly the effect of carbon templates on the silanol to siloxane of the silica-pectin (Si-pectin) and silica-P123 (Si-P123) matrices were analysed by the FTIR-ATR technique. The FTIR spectra was measured in the region of $1400-700 \mathrm{~cm}^{-1}$ as shown at Fig 2 (a) the characteristic peaks of siloxane ( $\mathrm{Si}-\mathrm{O}-\mathrm{Si}$ ) groups at $\sim 1070 \mathrm{~cm}^{-1}$ and the shoulders assigned to silanol (Si-OH) groups $976 \mathrm{~cm}^{-1}$ (Si-Pectin) and $962 \mathrm{~cm}^{-1}$ (Si-P123). The deconvolution of silanol peaks at $\sim 960-970 \mathrm{~cm}^{-1}$ can be identified as the stretching mode of $\mathrm{Si}-\mathrm{C}$ and the wagging mode of carbon attached to $\mathrm{Si}$ [16]. The peaks at $1070 \mathrm{~cm}^{-1}$ are assigned to a symmetric bond stretching vibration of siloxane network $[4,17,18]$. Then for the carbon bonds vibration are around at $2001-2029 \mathrm{~cm}^{-1}$ for $\mathrm{C} \equiv \mathrm{C}$ and for the $\mathrm{C}-\mathrm{H}$ bonds at $3372 \mathrm{~cm}^{-1}$. It clearly can be seen that silanols concentration between silica-pectin and silica-P123 are much smaller than siloxanes concentration. These structures show the similarity of our previous work on pure silica membranes [19]. The silanol groups tend to formed smaller pore size (microporous) [20], while the mesoporous and macroporous were presented by siloxanes concentration [14, 19, 21]. The systematic incorporation of pectin was investigated by deconvolution of the bands at $976 \mathrm{~cm}^{-1}$ and $1070 \mathrm{~cm}^{-1}$ to calculate the peak area ratio of the silanols versus siloxane groups that is shown in Fig. 3(b). If compare to Si-P123 which is employed triblock copolymer Pluronic ${ }^{\circledR}$ P123 as carbon template agent. It also shows the similar peak of siloxane at $1070 \mathrm{~cm}^{-1}$ and silanol at $962 \mathrm{~cm}^{-1}$. Differentially, the siloxane groups of Si-pectin are much higher than SiP123 as shown in Fig. 3(a). It is a contrary with the explanation of our previous work Elma, Wang [5]. It was reported that with increasing the carbon template concentration tended the xerogels to form mesoporous materials due to the favoured the siloxane formation [5]. If the concentration of each pectin and P123 templated into silica networks, the pectin concentration is much lower than P123 (0.1 versus $35 \mathrm{wt} \%$, respectively). For that, we assume that the carbon linear chains connected by pectin is much smaller than linear carbon chains of P123. More explanation can be seen in schematic shown in Fig. 5.

(a)

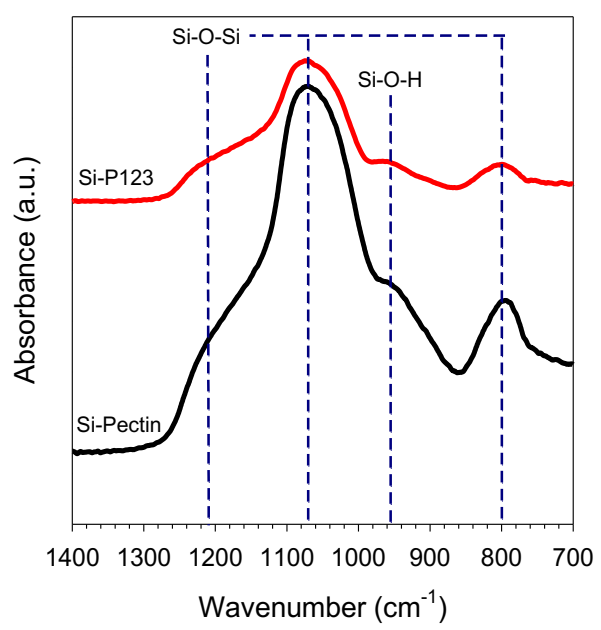

(b)

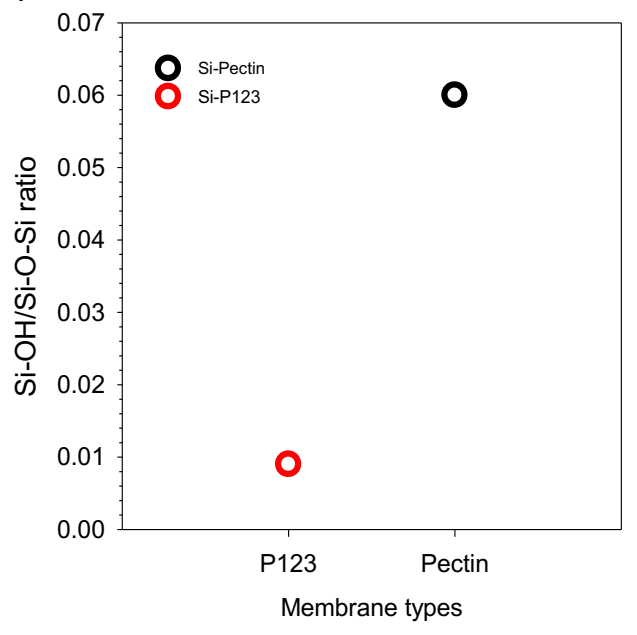

Fig. 3. (a) FTIR spectra of the calcined silica xerogels (b) peak area ratios between silanol and siloxane 


\subsection{Membrane performance}

Membrane performance were investigated using artificial seawater at room temperature $\left(\sim 25^{\circ} \mathrm{C}\right)$. As shown from Fig.4 silica-pectin membrane shows higher flux $5.79 \mathrm{~kg} \cdot \mathrm{m}^{-2} \cdot \mathrm{h}^{-1}$ than silica-P123 membrane even though both of them give the excellent salt rejection $(>99.9 \%)$. The water flux of silica-pectin membranes is three times higher than silica-P123 membrane. It proves that the silica-pectin membrane is more promising than silica-P123 membrane. Also with regard to materials used, the pectin was much smaller than P123 templates during membranes fabrication. This is a key to reduce more cost throughout fabrication.

A part from that, the salt rejection between these two membranes clearly shown that salt rejection of silica-pectin is higher than silica-P123 membranes (99.99 and 99\%, respectively). This silica-pectin membrane is very promising to develop in large scale where carbon source of this pectin was from apple which is very easy to earn.

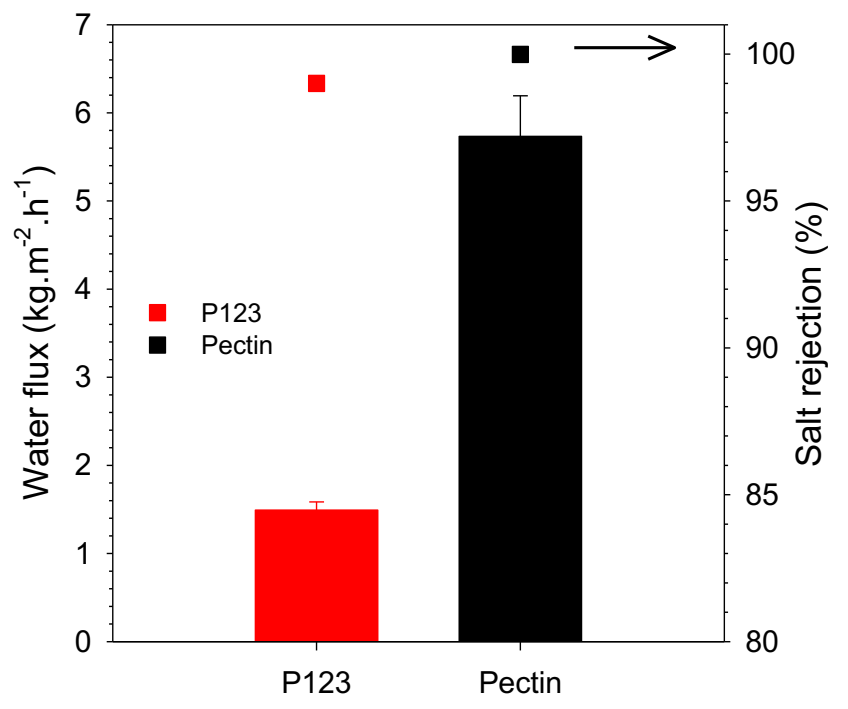

Membrane type

Fig. 4 Desalination performance of P123 silica template and Pectin silica template membranes as a function of water flux and salt rejection at feed temperature of $25^{\circ} \mathrm{C}$

Table 1 summarizes the multiples silica-carbon membranes with various calcination techniques, feed temperatures desalination via pervaporation operations, water fluxes and salt rejections. There are two different calcination techniques, such as, rapid and conventional thermal processing. Also, the feed temperatures were varied between $25^{\circ} \mathrm{C}$ and $60{ }^{\circ} \mathrm{C}$. The highest result of water fluxes is shown for work done by Song, Wang [22] and Yang, Elma [21] high water flux (20 and $\left.19.3 \mathrm{~kg} \cdot \mathrm{m}^{-2} \cdot \mathrm{h}^{-1}\right)$ is because they were used different type of membranes (carbon alumina mixed matrix membranes [22] and also worked under high feed temperatures $\left(60^{\circ} \mathrm{C}\right)$ [21]. On the other hand, water flux of silicapectin membranes from our work is excellently shown the highest water flux if compare to other silica-carbon membranes done by other researchers [4, 5, 23]. Sadly, for water flux of silica-P123 from our works shows low value compare to work done by other researchers (varied from 1.9 to $3.7 \mathrm{~kg} \cdot \mathrm{m}^{-2} \cdot \mathrm{h}^{-1}$ ). 
Table 1. Performa silica-pectin membrane in Seawater Desalination

\begin{tabular}{|l|c|c|c|c|c|c|}
\hline Membrane type & $\begin{array}{c}\text { Calcination } \\
\text { techniques }\end{array}$ & $\begin{array}{c}\text { Feed } \\
\text { Temp. } \\
\left({ }^{\circ} \mathbf{C}\right)\end{array}$ & $\begin{array}{c}\text { Water } \\
\text { Flux } \\
\left(\mathbf{k g . m}^{-2} \mathbf{h}^{-1}\right)\end{array}$ & $\begin{array}{c}\text { Feed } \\
\text { concentration } \\
(\boldsymbol{\%})\end{array}$ & $\begin{array}{c}\text { Rejection } \\
(\%)\end{array}$ & Ref. \\
\hline $\begin{array}{l}\text { Silica-pectin } \\
\text { membranes }\end{array}$ & RTP & 25 & 5.73 & 3.5 & $>99$ & $\begin{array}{c}\text { This } \\
\text { work }\end{array}$ \\
\hline $\begin{array}{l}\text { Silica-P123 } \\
\text { membranes }\end{array}$ & RTP & 25 & 1.49 & 3.5 & 99.8 & $\begin{array}{c}\text { This } \\
\text { work }\end{array}$ \\
\hline $\begin{array}{l}\text { Carbon silica } \\
\text { membrane }\end{array}$ & RTP & 60 & 19.3 & 3.5 & 99 & {$[21]$} \\
\hline $\begin{array}{l}\text { Carbon alumina } \\
\text { mixed matrix } \\
\left.\text { (CMS-Al } \mathrm{O}_{3}\right)\end{array}$ & RTP & 25 & 20 & 3.5 & $>99$ & {$[22]$} \\
\hline $\begin{array}{l}\text { Carbonized } \\
\text { template } \\
\text { membranes }\end{array}$ & CTP & 25 & 2.2 & 3.5 & $>99$ & {$[5]$} \\
\hline $\begin{array}{l}\text { Triblock } \\
\text { copolymer } \\
\text { templated silica } \\
\text { membranes }\end{array}$ & CTP & 25 & 3.7 & 3.5 & 98.5 & {$[23]$} \\
\hline $\begin{array}{l}\text { Carbon template } \\
\text { silica } \\
\text { membranes } \\
\text { (C16) }\end{array}$ & CTP & 25 & 3.4 & 3.5 & 97.5 & {$[4]$} \\
\hline $\begin{array}{l}\text { Carbon template } \\
\text { silica } \\
\text { membranes (C6) }\end{array}$ & CTP & 25 & 1.9 & 3.5 & 97 & {$[4]$} \\
\hline
\end{tabular}

Schematic shown in Fig.5 is clearly explained the carbon chains are templated into silica thin film and alumina substrates. Due to too many carbon chains of P123 connected between silica matrices, hence, the membranes layers become too thick as reported in our previous work [5]. From the water flux of our result, it shows there is a tendency of creating dense film of silica-P123 membranes during calcination if compare to silica-pectin membranes. It may assume from the number of carbon chains content in each material (P123 and pectin).

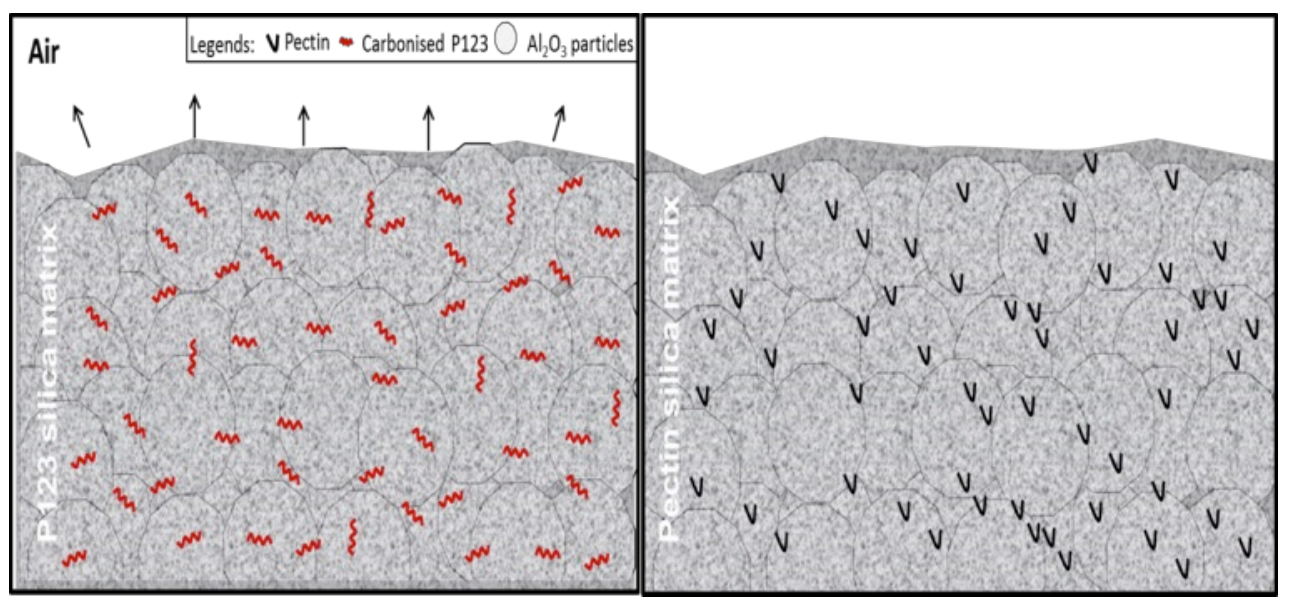

Fig. 5 Schematic of silica-carbon templated by P123 and pectin 
Moreover, silica-pectin membranes on the other hand give the strengthens to silica structures. Non-ionic micelles formed by pectin is much lower than P123. It is because the carbon number of pectin is much lower than P123. This micelle works is to interpenetrate the inorganic network [5].

\section{Conclusion}

Silica-carbon membranes templated from pectin and P123 were produced from dual catalyst acid and base sol gel method. The $0.1 \mathrm{wt} \%$ pectin as well as $35 \mathrm{wt} \% \mathrm{P} 123$ have been templated into silica sols and calcined in air at 400 and $350{ }^{\circ} \mathrm{C}$, respectively. The water fluxes of those membranes are 5.73 and $1.49 \mathrm{~kg} \cdot \mathrm{m}^{-2} \cdot \mathrm{h}^{-1}$. Silica-pectin membranes is a promising membrane which show excellent performance compare to silica-P123 membranes. The number of carbon chains of P123 connected to silica networks create dense film of membranes.

\section{Acknowledgement}

The authors acknowledge to the financial support research grant (PNBP 2018) and the facilities of Process Technology Laboratory, Engineering Faculty, Lambung Mangkurat University. Muthia Elma thanks to Post-Doctoral Grant 2018, Directorate of Research and Community Service, the Ministry of Research, Technology and Higher Education Republic of Indonesia. and Australian Indonesian Project (ANU) Indonesian Project and SMERU Research Institute Research Grants 2016-2017.

\section{References}

1. Ahmad. S.A. and Lone S.R. Int. J. Sci.\& Engin. Res. 3. (2012)

2. M. Elma, C. Yacou, D. K. Wang, S. Smart, and J. C. Diniz da Costa. Water. 4. 629649. (2012)

3. J. C. Diniz da Costa, G. Q. Lu, V. Rudolph, and Y. S. Lin. Journal of Membrane Science. 198. 9-21. (2002)

4. S. Wijaya, M. C. Duke, and J. C. Diniz da Costa. Desalination. 236. 291-298. (2009)

5. M. Elma, D. K. Wang, C. Yacou, and J. C. Diniz da Costa. Journal of Membrane Science. 475. 376-383. (2015)

6. M. Elma, D. K. Wang, C. Yacou, J. Motuzas, and J. C. Diniz da Costa. Desalination. 365. 308-315. (2015)

7. N. Z. K. Shaari, N. A. Rahman, and R. M. Tajuddin. Thin film composite membrane with hybrid membrane as the barrier layer: Preparation and characterization. in 2012 IEEE Colloquium on Humanities, Science and Engineering (CHUSER). 2012.

8. M. M. Titirici, R. J. White, N. Brun, V. L. Budarin, D. S. Su, F. del Monte, J. H. Clark, and M. J. MacLachlan. Chemical Society Reviews. 44. 250-290. (2015)

9. C. A. Perussello, Z. Zhihang, M. Antonio, and B. K. Tiwari. Comprehensive Reviews in Food Science and Food Safety. 16. 776-796. (2017)

10. A. Lagazzo, E. Finocchio, P. Petrini, C. Ruggiero, and L. Pastorino. Materials Letters. (2016)

11. B. C. Bonekamp, Chapter 6 Preparation of asymmetric ceramic membrane supports by dip-coating, in Membrane Science and Technology, A.J. Burggraaf and L. Cot, Editors. 1996, Elsevier. p. 141-225. 
12. M. Elma, D. K. Wang, C. Yacou, and J. C. Diniz da Costa. J. Mem. Sci. 475. 376-383. (2015)

13. D. K. Wang, J. Motuzas, J. C. Diniz da Costa, and S. Smart. International Journal of Hydrogen Energy. 38. 7394-7399. (2013)

14. S. Wang, D. K. Wang, J. Motuzas, S. Smart, and J. C. Diniz da Costa. Journal of Membrane Science. 516. 94-103. (2016)

15. S. Wang, D. K. Wang, S. Smart, and J. C. Diniz da Costa. Desalination. 402. 25-32. (2017)

16. H. Wieder, M. Cardona, and C. R. Guarnieri. phys. stat. sol. (b). (b). 92-112. (1979)

17. M. Elma, D. K. Wang, C. Yacou, and J. C. Diniz da Costa. Journal of Membrane Science. 475. 376-383. (2015)

18. A. Bertoluzza, C. Fagnano, M. A. Morelli, V. Gottardi, and M. Guglielmi. Journal of Non-Crystalline Solids. 48. 117-128. (1982)

19. M. Elma, C. Yacou, J. Costa, and D. Wang. Membranes. 3. 136-150. (2013)

20. C. X. C. Lin, Li P. Ding, S. Smart, and J. C. Diniz da Costa. Journal of Colloid and Interface Science. 368. 70-76. (2012)

21. H. Yang, M. Elma, D. K. Wang, J. Motuzas, and J. C. Diniz da Costa. Journal of Membrane Science. 523. 197-204. (2017)

22. Y. J. Song, D. K. Wang, G. Birkett, W. Martens, M. C. Duke, S. Smart, and J. C. Diniz da Costa. Scientific Reports. 6. 30703. (2016)

23. B. P. Ladewig, Y. H. Tan, C. X. C. Lin, K. Ladewig, J. C. Diniz da Costa, and S. Smart. Materials. 4. (2011) 